\title{
Knowledge and Awareness of Breast Cancer among Young Women in the United Arab Emirates
}

\author{
Moustafa Younis*, Dania Al-Rubaye, Hadeel Haddad, Ahmed Hammad, Manar Hijazi \\ College of Medicine, University of Sharjah (UOS), Sharjah, United Arab Emirates \\ Email: *u00022147@sharjah.ac.ae
}

How to cite this paper: Younis, M., AlRubaye, D., Haddad, H., Hammad, A. and Hijazi, M. (2016) Knowledge and Awareness of Breast Cancer among Young Women in the United Arab Emirates. Advances in Breast Cancer Research, 5, 163176.

http://dx.doi.org/10.4236/abcr.2016.54019

Received: October 5, 2016

Accepted: October 28, 2016

Published: October 31, 2016

Copyright $\odot 2016$ by authors and Scientific Research Publishing Inc. This work is licensed under the Creative Commons Attribution International License (CC BY 4.0).

http://creativecommons.org/licenses/by/4.0/

\section{(c) (i) Open Access}

\begin{abstract}
Background: Breast cancer is the most common cancer among females in the United Arab Emirates (UAE). It carries poor prognosis when detected late. Patients usually present at late stages due to lack of awareness of various aspects of breast cancer. Aim: The objective of this study is to gain insight into the level of knowledge of breast cancer among young adult females in UAE. Methods: A cross-sectional study was conducted among females aged 25 to 45 . A total of 492 females were selected using a convenience sampling method. Data were collected through an interview-based questionnaire. Frequency distributions and percentages were used to describe the knowledge tested within the questionnaire. Results: The mean age of the participants was 33.5 years. Almost $27 \%$ of our participants received a high school degree. The average total knowledge of our population was $51 \%$. The majority $(89 \%)$ knew that breast cancer is common and $45 \%$ knew that it affects ages above forty. The knowledge of signs and symptoms was 53\%, and more than half (57\%) knew that the most common presenting sign is a breast lump. The knowledge of risk factors was 43\%. Almost $94 \%$ knew that cancer can be detected early, and $93 \%$ knew that early diagnosis improves outcome. The total knowledge of screening methods was $67 \%$. Conclusion: The study revealed that respondents' knowledge of breast cancer is less than expected. The increased burden of the disease should be accompanied by powerful means of spreading awareness by implementing campaigns that would improve knowledge deficits.
\end{abstract}

\section{Keywords}

Breast Cancer, Awareness, Knowledge, Breast Self-Examination, Clinical Breast

Examination, Young Adults, UAE

\section{Introduction}

Breast cancer is the most common cancer in the United Arab Emirates, accounting for 
$22.8 \%$ of all cancer cases (UAE Ministry of Health, 2010) [1]. The main obstacle encountered when dealing with breast cancer is its subtle symptoms; hence it is usually diagnosed at a late stage where cure chances are much lower. In fact, only $30 \%$ of cases in the UAE-a lower number than in most western countries-are diagnosed in the early stages $[1]$.

Breast cancer is affected by multiple risk factors, including family history/genetic background, hormonal exposures, such as: an early age at menarche, late age at menopause, fewer number of children and null parity, late age at first birth, little or no breastfeeding and long-term use of hormone replacement therapy

Signs of breast cancer may include a palpable breast lump, nipple discharge and skin changes. Mammography detecting early signs of the disease is a valuable diagnostic test, while a pathological examination of a biopsy (fine needle aspiration (FNA), core biopsy, ultrasound-guided core biopsy, stereotactic biopsy, open excisional biopsy, and sentinel node biopsy) from a breast lump aids in differentiation of the types of cancer and survival rate. Breast cancer prognosis and treatment depend on tumor-node-metastasis staging, lymphovascular spread, histological grade, hormone receptor status, comorbidities, and the patient's menopausal status. Generally, treatment includes surgical removal of the breast tissue, chemotherapy, hormone therapy, and radiotherapy (Maughan et al. 2010) [2].

There are various breast cancer screening tests. That includes self-breast examination, clinical breast examination and most importantly regular mammograms. Mammography has been proven to have the strongest impact in decreasing mortality and morbidity (US Department of Health and Human Services, 2000) [3]. The United States Preventive Services Task Force (USPSTF) [4] recommends biennial screening mammography for women aged 50 to 74 years.

Although it is known that breast cancer affects older age groups, the age threshold is gradually decreasing. According to the National Institute of Cancer statistics [5], there is a lower survival rate amongst women diagnosed below the age of forty, eminently that the cancer diagnosed in young women tends to be more aggressive with a higher mortality rate.

The recent fall of death from breast cancer in western nations is particularly explained by earlier diagnosis as a result of early presentation. It has been demonstrated that delayed presentation of symptomatic breast cancer for several months ( $\geq 3$ months) from the first detection to the time of diagnosis and treatment has been associated with increased tumor size (Richards. et al. 1999) [6] and poor long-term survival (Rossi 1990) [7]. The negative sociocultural perception of breast cancer, strong beliefs in traditional medicine and perhaps strong religious beliefs are the main reasons for the delay in presentation in the Arab world and developing countries (Rashidi et al. 2000) [8] (Rajaram et al. 1999) [9]. It has been demonstrated that the majority of breast cancer cases in the UAE are diagnosed late with involvement of regional lymph nodes or distant metastasis (Al-Sharbatti et al. 2013) [10].

The main aim of this research is to gain insight on the level of awareness of breast 
cancer among young adult females in the UAE; hence assessing if there is a need to implement interventional programs to encourage and increase awareness of breast cancer based on the identified level of knowledge. Several studies have been conducted in different emirates in the UAE to investigate women's knowledge and their awareness of breast cancer in different age groups (Elobaid et al. 2014) [11]; (Abduelkarem et al. 2015) [12]. However, none of these studies were aimed at the UAE as a whole. In addition, we strongly emphasized on the "golden age" for awareness by targeting the young adult female population only. Public education about a disease is pragmatic and simple, yet a pivotal tool that would help in early detection and would subsequently improve the prognosis by providing better chances for successful treatments and definitive cures.

\section{Methodology}

\subsection{Study Design}

A descriptive cross-sectional survey was used to conduct this research.

\subsection{Ethical Consideration}

All the necessary approvals for carrying out the research were obtained. The Deanship of Scientific Research Ethics Committee at the University of Sharjah approved the study protocol. In addition, each questionnaire included a written informed consent demonstrating the researchers' names and explaining the objective and protocol of the research. The informed consent was signed by all participants. Privacy and confidentiality were insured. Study subjects were permitted to withdraw from the research at any time and their responses were considered invalid and discarded. There were no further requirements to obtain ethical approval for this study in the UAE.

Moreover, the topic of the research may have caused a slight conflict with the society's cultural and moral values. As the research is about breast cancer, the topic might be a sensitive one to discuss with some participants. In order to minimize discomfort among the female participants, the interviews were held by the female members of the research team.

\subsection{Study Subjects and Sampling}

The sample was selected based on a convenience sampling method. Inclusion criteria includes: adult females between 25 and 45 years of age that were available at the time of data collection in community centers, health care centers, entertainment centers-malls, family relations, teaching faculty. Exclusion criteria: Personal history of breast cancer, family history of breast cancer. Eligibility for the study was screened for using the consent form in the questionnaire. Data were collected from February 2nd, 2013 until March 1st, 2013. A sample size calculator was used to estimate the number of participants in our study in order to get results that reflect the target population as precisely as needed. The confidence level and interval chosen were $95 \%$ and 5 respectively. The calculator uses the Kish Leslie formula. The calculation also considered 
a $10 \%$ nonresponse rate. The calculated sample size was 472 . However, erroneusly a larger sample of 492 respondents was collected.

\subsection{Data Collection}

An interview-based questionnaire was designed to be used as the instrument for data collection. The questionnaire included 66 questions that were a combination of closed ended and open-ended questions. The questions aimed at recording the demographics of the respondents as well as, their knowledge of breast cancer epidemiology, risk factors, signs and symptoms; and methods of screening, in addition to their screening behavior. The knowledge section of the questionnaire was developed based on information in the literature on the pertaining topics. The questionnaire was then reviewed by a Breast Surgeon, an oncologist and four Gynecologists from the University Hospital of Sharjah. Their review comments were then incorporated into the revised questionnaire.

A pilot study with 20 respondents was conducted two weeks prior to data collection in order to test the reliability and validity of the questionnaire, and changes were done accordingly. The data collected from the pilot study was not included in the research.

Participants underwent verbal face-to-face interviews; performed by the investigators to insure the quality of data collection e.g., disregarding or misunderstanding questions, the skip pattern in questions .etc.

\subsection{Study Variables}

The socio-demographic data (seven questions) included age in years, nationality (locals, non local arabs, or non-arabs), marital status (single, married, widowed, and divorced), beared children or not, educational level (Intermediate, Secondary University, Masters, $\mathrm{PhD}$ or Other), occupation (housewife vs. Medical job vs non medical job) and family history of breast cancer.

The knowledge variables were based on closed ended multiple choice questions, including questions about the epidemiology (six questions), knowledge and practice of breast cancer screening (13 questions), including mammography, breast self-examination (BSE), and clinical examination. A table containing the most common risk factors was used to evaluate the level of knowledge of risk factors. The participants were asked if these risk factors were present (documented as a positive respondant), absent (documented as a negative respondant) or if they did not know. A similar table was collected for the most common signs and symptoms. The study questionnaire also included questions about the obstacles and barriers preventing women from undergoing a mammography and sources of information for the pertaining knowledge.

The questionnaires where then corrected by comparing the answers with a fixed answering scheme that we developped. An average score in percent was then calculated for each patient using this equation ((\#corrrect answers/66)*100) and subsequently for the whole population. The latter score represents the average level of total knowledge in our whole population of participants. Participants were also grouped based on their level of knowledge into poor $(<35 \%)$, moderate $(36 \%<\mathrm{x}<70 \%)$ and good $(>70 \%)$. 


\subsection{Statistical Analysis}

Upon data entry, participants' incomplete questionnaires were discarded. Data analysis was achieved using the SPSS (statistical package for social sciences) version 20. Continuous data is presented with a mean \pm standard deviation (and quantiles as appropriate). Categorical data are presented as counts and percentages; the chi-square test was used to assess for an association between two categorical variables. In our study, Chi square was used to identify any significant differences among participants in the level of knowledge between different age groups, marital status and nationalities. Associations between continuous and categorical variables were measured with a t-test, and correlation between two continuous variables was assessed with a spearman's rank correlation coefficient. Correlation tests were applied when comparing level of knowledge with the educational status. The data analyzed were then presented using tables and figures.

\section{Results}

A total of 492 respondents met the inclusion and exclusion criteria and were therefore included in the study. All respondents had complete questionnaires. The response rate was a $100 \%$.

The mean age of the participants was 33.5 years $(\mathrm{SD}=6.9$, range $=25-45)$, where almost half (44.7\%) were of ages 25 - 30. A percentage of $26.8 \%$ of participants did not continue their education following high school, the rest were all of higher education (bachelor degree, masters, $\mathrm{PhD}$ ). The percentage of illiteracy in our population is $0 \%$. The demographic characteristics have been presented in Table 1.

The average total knowledge of all our population about breast cancer was $51 \%$ (Table 2).

Participants were then grouped based on their total level of knowledge into poor (13\%), moderate (77\%) and good (10\%) (Figure 1).

Majority of the population (89\%) knew that breast cancer is common among females; $45 \%$ knew that breast cancer affects ages above forty. The percentage of participants that knew that breast cancer affect males is 55\%. In addition, 55\% of females didn't know how common breast cancer is in the UAE (Table 3).

The total knowledge of signs and symptoms was 53\% (Figure 1). More than half of the targeted population (58\%) knew that the commonest presenting sign is a lump in the breast or under the armpit (Table 4) and $90 \%$ of the participants reported that a lump is a sign of breast cancer (Table 5). Signs and symptoms of breast cancer that participants were tested on are included in (Table 5) along with the positive number of respondents and its corresponding percentage.

The total knowledge of risk factors was $43 \%$, which was least among all the other compared aspects of knowledge (Table 2). Advanced age was identified as a risk factor for breast cancer in $67 \%$ of the respondents. On the other hand, $78 \%$ identified genetics a risk factor (Table 6). Knowledge of different risk factors of breast cancer was included in Table 6.

The total knowledge of the different aspects of diagnosis and early detection methods 
Table 1. Participants' demographics.

\begin{tabular}{|c|c|c|}
\hline Demographic characteristics & Respondents & Percentage \\
\hline \multicolumn{3}{|l|}{ Age distribution of the respondents } \\
\hline$<35$ & 284 & $57.7 \%$ \\
\hline$\geq 35$ & 208 & $42.3 \%$ \\
\hline Total & 492 & $100 \%$ \\
\hline \multicolumn{3}{|l|}{ Marital Status of the respondents } \\
\hline Single & 184 & $37.4 \%$ \\
\hline Married & 282 & $57.3 \%$ \\
\hline Divorced & 14 & $2.8 \%$ \\
\hline Widowed & 4 & $0.8 \%$ \\
\hline Separated & 8 & $1.6 \%$ \\
\hline Total & 492 & $100 \%$ \\
\hline \multicolumn{3}{|l|}{ Having children of the respondents } \\
\hline Yes & 438 & $88.5 \%$ \\
\hline No & 54 & $11.5 \%$ \\
\hline Total & 492 & $100 \%$ \\
\hline \multicolumn{3}{|l|}{ Level of education of the respondents } \\
\hline Intermediate & 15 & $3 \%$ \\
\hline Secondary & 106 & $21.5 \%$ \\
\hline University & 326 & $66.3 \%$ \\
\hline Masters & 28 & $5.7 \%$ \\
\hline $\mathrm{PhD}$ & 6 & $1.2 \%$ \\
\hline Other & 11 & $2.2 \%$ \\
\hline Total & 492 & $100 \%$ \\
\hline \multicolumn{3}{|l|}{ Occupation of the respondents } \\
\hline Medical job & 87 & $17.8 \%$ \\
\hline Non-medical & 227 & $46.3 \%$ \\
\hline No job & 178 & $35.9 \%$ \\
\hline Total & 492 & $100 \%$ \\
\hline \multicolumn{3}{|l|}{ Nationality of the respondents } \\
\hline Local (Emirati) & 102 & $20.7 \%$ \\
\hline Arabs & 304 & $62 \%$ \\
\hline Non Arabs & 86 & $17.4 \%$ \\
\hline Total & 492 & $100 \%$ \\
\hline \multicolumn{3}{|c|}{$\begin{array}{l}\text { Having family history of breast cancer among the } \\
\text { respondents }\end{array}$} \\
\hline Yes (exclusion criteria) & 0 & $0 \%$ \\
\hline No & 472 & $95.9 \%$ \\
\hline I don't know & 20 & $4.1 \%$ \\
\hline Total & 492 & $100 \%$ \\
\hline
\end{tabular}

was $67 \%$ (Figure 1). Approximately $88 \%$ of the participants were aware that breast cancer can be detected using screening tools. In addition, $83 \%$ reported the breast cancer can be curable if detected early (Table 7). Mammography was identified as a screening tool for breast cancer in $44 \%$ but only $18 \%$ performed mammography at any point in their lives (Table 8).

The most common cause of reluctance in performing self-breast examination was 


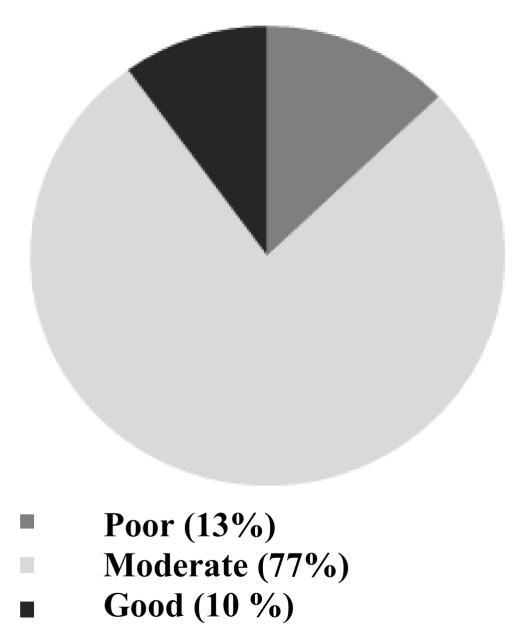

Figure 1. Participants' level of knowledge of breast cancer.

Table 2. Participants' average level of knowledge in the tested domains.

\begin{tabular}{cc}
\hline Domain & Percentage \\
\hline Prevention, diagnosis, and treatment & $67 \%$ \\
Risk factors & $43 \%$ \\
Signs and symptoms & $53 \%$ \\
Epidemiology & $53 \%$ \\
Total Knowledge & $51 \%$ \\
\hline
\end{tabular}

lack of time. More importantly, $21 \%$ of our participants did not believe they were at risk (Table 9).

The most common source of information for our participants' knowledge was Radio/Television at $64 \%$. Family physicians were a source of information in $30 \%$ of the female volunteers (Table 10).

There was no significant difference in the level of knowledge between the different age groups ( $\mathrm{p}=0.09,95 \% \mathrm{CI}=-4.99-0.34)$, nor between married and single participants $(\mathrm{p}=0.10,95 \% \mathrm{CI}=-5-0.42)$. In addition, there was no significant difference in the level of knowledge between nulliparous, uniparous and multiparous women. ( $\mathrm{p}=$ $0.07,95 \% \mathrm{CI}=-2.34-2.87)$. There was a weak positive correlation $(\mathrm{p}=0.02, \mathrm{R}=0.105)$ between the total knowledge and educational level of the participants. There was no significant difference in the level of knowledge between females of medical jobs and housewives. ( $\mathrm{p}=0.14,95 \% \mathrm{CI}=-4.79$ - 0.29).

In addition, there was a higher total level of knowledge in Arab ex-pats in comparison to UAE nationals $(\mathrm{p}=0.02,95 \% \mathrm{CI}=-9.8-9.87)$.

\section{Discussion}

The estimated level of respondents' general knowledge is $51 \%$. Most of our respondents were in the average score category (77\%). This result is satisfying, especially since in comparison with Kashmir in Pakistan (Salat et al. 2010) [13], their percentage of res- 
Table 3. Participants' knowledge of breast cancer epidemiology.

\begin{tabular}{|c|c|c|}
\hline Breast cancer epidemiology & Respondents & Percentage \\
\hline \multicolumn{3}{|l|}{ Breast cancer affects males } \\
\hline Yes & 269 & $54.6 \%$ \\
\hline No & 125 & $25.5 \%$ \\
\hline I don't know & 98 & $20 \%$ \\
\hline Total & 492 & $100 \%$ \\
\hline \multicolumn{3}{|l|}{ Common cancer in females } \\
\hline Yes & 439 & $89.2 \%$ \\
\hline No & 35 & $7.1 \%$ \\
\hline I don't know & 18 & $3.7 \%$ \\
\hline Total & 492 & $100 \%$ \\
\hline \multicolumn{3}{|c|}{ Incidence of breast cancer worldwide } \\
\hline$<30 \%$ & 38 & $7.6 \%$ \\
\hline $30 \%-49 \%$ & 125 & $25.2 \%$ \\
\hline $50 \%-60 \%$ & 117 & $23.7 \%$ \\
\hline $61 \%-80 \%$ & 44 & $8.9 \%$ \\
\hline I don't know & 1168 & $34.6 \%$ \\
\hline Total & 492 & $100 \%$ \\
\hline \multicolumn{3}{|c|}{ Incidence of breast cancer in the U.A.E. } \\
\hline$<10 \%$ & 4 & $0.8 \%$ \\
\hline $10 \%-20 \%$ & 27 & $5.5 \%$ \\
\hline $21 \%-30 \%$ & 57 & $11.6 \%$ \\
\hline $31 \%-40 \%$ & 68 & $13.9 \%$ \\
\hline $41 \%-50 \%$ & 65 & $13.3 \%$ \\
\hline I don't know & 271 & $54.9 \%$ \\
\hline Total & 492 & $100 \%$ \\
\hline \multicolumn{3}{|c|}{ Age group of highest incidence of breast cancer } \\
\hline $16-30$ & 27 & $5.5 \%$ \\
\hline $31-40$ & 179 & $36.2 \%$ \\
\hline$>40$ & 222 & $45.4 \%$ \\
\hline I don't know & 64 & $12.9 \%$ \\
\hline Total & 492 & $100 \%$ \\
\hline \multicolumn{3}{|l|}{ Breast cancer is inherited } \\
\hline Yes & 348 & $70.7 \%$ \\
\hline No & 85 & $17.3 \%$ \\
\hline I don't know & 59 & $12 \%$ \\
\hline Total & 492 & $100 \%$ \\
\hline
\end{tabular}

Table 4. What is the most common sign or symptom of breast cancer?

\begin{tabular}{cc}
\hline Sign/Symptom & Percentage \\
\hline Lump (breast or axilla) & $58 \%$ \\
Breast pain & $18 \%$ \\
Nipple discharge & $9 \%$ \\
One breast larger than the other & $7 \%$ \\
I don't know & $7 \%$ \\
Others & $1 \%$
\end{tabular}


Table 5. Participants' knowledge of breast cancer signs and symptoms.

\begin{tabular}{ccc}
\hline Signs \& Symptoms & Actual (n) of positive respondents & Percentage \\
\hline Lump in breast & 446 & $90.7 \%$ \\
Lump in axilla & 378 & $76.8 \%$ \\
Breast pain & 321 & $65.6 \%$ \\
Nipple discharge & 280 & $57 \%$ \\
One breast larger than the other & 322 & $65.7 \%$ \\
\hline
\end{tabular}

Table 6. Participants' knowledge of breast cancer risk factors.

\begin{tabular}{ccc}
\hline Risk Factors & Actual (n) of positive respondents & Percentage \\
\hline Advanced age & 328 & $67.4 \%$ \\
Oral contraceptive pills & 234 & $48 \%$ \\
Genetics & 381 & $77.6 \%$ \\
Obesity & 184 & $37.7 \%$ \\
Early menarche & 139 & $28.4 \%$ \\
Late menopause & 147 & $30.1 \%$ \\
Hormone therapy & 288 & $58.9 \%$ \\
Ovarian cancer & 205 & $42.1 \%$ \\
Smoking & 293 & $59.8 \%$ \\
Physical trauma & 125 & $25.7 \%$ \\
Lack of breast feeding & 177 & $23.9 \%$ \\
\hline
\end{tabular}

pondents in the moderate category was $12.3 \%$, while according to Georgia R Sadler (2007) [14] 50\% where in the "moderate" category and 31\% in the "above average" category in the United States. However, being a country of high education and economic status in comparison to its region, we expected a higher percentage in the "above average" section.

Aging and null parity are considered major risk factors of breast cancer. Therefore, nulliparous females and/or women of older age are expected to be more aware of their increased risk in comparison to the general population, yet there was no significant difference in the level of knowledge in different age groups. In addition, there was no significant difference in the level of knowledge between nulliparous, uniparous or multiparous participants. Similar results were shown by Somdatta et al. (2008) [15].

There was a weak positive correlation between knowledge and educational level. It was seen that the proportion of women who were aware increased as the literacy status increased, and this was statistically significant. However, absence of illiterate participants played a role by masking the effect of educational variance on knowledge. Existing research supports our expectations as they suggest that populations with lower educational and socioeconomic status have lower cancer awareness (Brunswick et al., 2001) [16] (Wardle et al., 2001) [17]. 
Table 7. Participants' knowledge of breast cancer prevention.

\begin{tabular}{|c|c|c|}
\hline Knowledge of prevention of breast cancer & Respondents & Percentage \\
\hline \multicolumn{3}{|l|}{ Screening methods for breast cancer } \\
\hline Yes & 422 & $88.1 \%$ \\
\hline No & 70 & $11.9 \%$ \\
\hline Total & 492 & $100 \%$ \\
\hline \multicolumn{3}{|l|}{ Performing self-breast examination } \\
\hline Yes & 388 & $78.9 \%$ \\
\hline No & 104 & $21.1 \%$ \\
\hline Total & 492 & $100 \%$ \\
\hline \multicolumn{3}{|l|}{ Age to start practicing self-breast examination } \\
\hline $10-19$ & 19 & $4.8 \%$ \\
\hline $20-29$ & 212 & $43.4 \%$ \\
\hline $30-39$ & 148 & $30.3 \%$ \\
\hline 40 onwards & 75 & $15.3 \%$ \\
\hline I don't know & 29 & $6.3 \%$ \\
\hline Total & 492 & $100 \%$ \\
\hline \multicolumn{3}{|l|}{ Breast cancer is curable } \\
\hline Curable if detected early & 409 & $83 \%$ \\
\hline Non curable & 20 & $4.1 \%$ \\
\hline Curable & 36 & $7.4 \%$ \\
\hline I don't know & 27 & $5.5 \%$ \\
\hline Total & 492 & $100 \%$ \\
\hline \multicolumn{3}{|l|}{ Early diagnosis improves treatment outcome } \\
\hline Yes & 461 & $93.7 \%$ \\
\hline No & 8 & $1.6 \%$ \\
\hline I don't know & 23 & $4.7 \%$ \\
\hline Total & 492 & $100 \%$ \\
\hline
\end{tabular}

Table 8. Participants' knowledge and practice of breast cancer screening methods.

\begin{tabular}{ccc}
\hline Examination/Investigation & Aspect & Percentage \\
\hline \multirow{2}{*}{ Self-breast examination } & Knowledge & $57 \%$ \\
& Practice & $49 \%$ \\
Clinical examination & Knowledge & $59 \%$ \\
& Practice & $29 \%$ \\
Mammography & Knowledge & $44 \%$ \\
& Practice & $18 \%$ \\
\hline
\end{tabular}

Table 9. Participants' Causes of reluctance in performing breast self-examination.

\begin{tabular}{cc}
\hline Cause & Percentage \\
\hline Lack of time & $22.2 \%$ \\
Not at risk & $21.3 \%$ \\
Fear of finding abnormality & $15 \%$ \\
Didn't know about that & $14.2 \%$ \\
Never attended any demonstrations & $14 \%$ \\
Don't know the appropriate way & $11 \%$ \\
Lack of privacy & $5 \%$ \\
Not convinced of its importance & $3 \%$ \\
\hline
\end{tabular}


Table 10. Participants' sources of information about breast cancer.

\begin{tabular}{cc}
\hline Source & Percentage \\
\hline Radio, TV & $64.2 \%$ \\
Printed materials & $52.2 \%$ \\
Friends & $47 \%$ \\
Family physicians & $29.9 \%$ \\
Colleagues & $32.1 \%$ \\
Internet & $51 \%$ \\
Governmental campaigns & $41.3 \%$ \\
Others & $10.4 \%$ \\
\hline
\end{tabular}

Respondents of medical professions had slightly higher level of knowledge (57\%) compared to others of different occupations $48 \%$. But this difference was not statistically significant $(\mathrm{p}=0.14,95 \% \mathrm{CI}=-4.79-0.29)$. Due to this unexpected low finding, recommendations for the intervening programs to target both medical and non-medical fields are required.

UAE locals showed lower knowledge levels than expatriates bringing attention to the importance of implementing awareness that target the local population more effectively. We hypothesize that the difference could be attributed to difference in cultural backgrounds.

The level of knowledge of risk factors was $43 \%$; this percentage was the least in comparison to other fields of knowledge. Likewise, several studies in the UK reported limited awareness of risk factors. In addition, knowledge of the warning signs was also poor, "in line with other research in the UK" (Wardle et al., 2001 [17]; Grunfeld et al., 2002 [18]; Waller et al., 2004 [19]; Robb et al., 2006 [20]).

Most of the respondents were generally aware of detection methods. On the contrary, smaller number had knowledge of proper age to start screening and performing BSE. $58 \%$ of the respondents knew about BSE, while only $49 \%$ performed it. According to Habib et al. (2010) [21] only $30.3 \%$ of the Saudi women knew about BSE versus $61 \%$ in Iran. Saudi Arabia was used as a comparison with the UAE due to the substantial overlap in cultures and beliefs in these two countries. In contrast, according to Shin-Ping Tu et al. (2006) [22], 75\% of females in the USA perform BSE (Figure 2).

Results showed that many respondents were reluctant in performing BSE or other screening methods. As for the cause, the most common response was due to the misperception of being at low risk, or not being aware of the incidence and risk factors of breast cancer. Similar to most researches, media (Table 10) was the most common source of knowledge [13]. Unlike media resources, physicians turned out to be of lower role (Table 10).

The strengths of this study include the questionnaire which was comprehensive and addressed nearly all knowledge items as well as a wide range of personal and belief barrier factors. Participants underwent verbal face-to-face interviews; performed by the investigators to insure the quality of data collection. The study questionnaire has also 


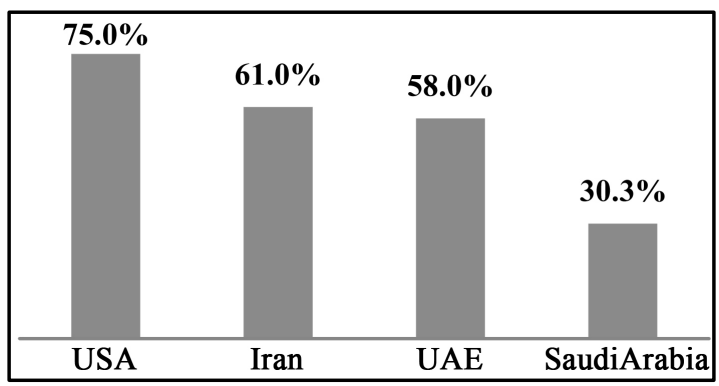

Figure 2. Knowledge of self-breast examination.

been validated by a Breast Surgeon, an oncologist and four Gynecologists from the University Hospital of Sharjah. Second of all, to the best of our knowledge, this study is the first study to investigate the knowledge, awareness and barriers of breast cancer screening in the UAE as a whole and not in certain emirates only. Therefore, our findings can be generalized to all females in the UAE. In addition, this is the first study in the UAE that has evaluated the level of knowledge in young adult females.

We acknowledge certain limitations of this study: Firstly, Non-random sampling lead to selection bias and affected the normal distribution of the characteristics of the sample population. The main characteristics that were affected by this bias were age (i.e., respondents were of age extremes), literacy (i.e., absence of illiterate respondents), and geographical location of the participants (i.e., covering limited areas in different emirates of the country).

Secondly, the following are questions that were asked in the detection and screening section of our questionnaire: Is breast cancer a detectable cancer? Do you think that a lady can check for breast cancer herself at home? Are you aware of how to check for breast cancer yourself? Have you ever performed a "Self-Breast Examination"? At which age (in years) should a lady start practicing "Self Breast Examination"? How frequently should the breast self-examination be done? How often is clinical breast examination done? Do you know what mammography is? At what age is mammography done?. The pattern of our questions was mainly exploring the knowledge of breast cancer screening and detection. In comparison with Somdatta et al. (2008) [15] and Godfrey et al. (2016) [23], our questionnaire lacked questions targeting personal practices of the screening methods mentioned. Thus, inaccurate conclusions may be inferred about the use of different breast cancer screening tools in our population.

For the mentioned limitations, generally the results may lead to overestimation of the awareness level of breast cancer in our study.

\section{Conclusions}

Analyzing the study's results revealed that respondents' knowledge of general aspects of breast cancer like risk factors, warning signs and symptoms, and screening behavior in the UAE is sufficient but lower than the expected level. This might be attributed to the insufficient contribution of health authorities and physicians in promoting awareness. Physicians turned out to be of less importance as a source of knowledge for the partici- 
pants. Therefore, it is necessary to enhance the role of health practitioners by training them in educating the women and keeping them updated about the disease and it's prevention.

The increased burden of breast cancer should be accompanied by powerful means of spreading awareness; which is the exact aim of the study. Therefore, it is important to encourage the implementation of programs and community based campaigns that cover knowledge deficits, in the general population, as well as emphasize the role of prevention of breast cancer through different screening methods. The prior can be achieved by setting out stands held by junior doctors that are informed about the topic; distributing flyers about breast cancer in public places. Advertisements on television and radio would also be a strong mean to deliver information.

Finally, we suppose that campaigns and programs alone are not sufficient; as information have to be spread in a form that better captures the population's attention, that's why we recommend the establishment of policy guidelines that shall spread adequate information about breast cancer to all women as soon as possible.

\section{Acknowledgements}

The authors would like to thank Mrs. Amal Hussein (lecturer in college of medicine, UOS), Dr. Nahed Abdelkhalek (associate Professor in college of Medicine, UOS), Dr. Toufiq Tabbara (assistant Professor in college of medicine, UOS), for their assistance and support.

\section{Conflict of Interest}

The authors declare no conflict of interest.

\section{References}

[1] Ministry of Health (2010) Beat Breast Cancer. United Arab Emirates.

[2] Maughan, K.L., Lutterbie, M.A. and Ham, P.S. (2010) Treatment of Breast Cancer. American Family Physician, 81, 1339-1346.

[3] US Department of Health and Human Services (2014) Breast Cancer Screening. Washington DC.

[4] The United States Preventive Services Task Force (USPSTF) (2011) Breast Cancer Screening. Rockville, Maryland.

[5] National Library of Medicine (2014) Breast Cancer. Rockville, Maryland.

[6] Richards M.A., Stockton D., Babb P. and Coleman M.P. (2000) How Many Deaths Have Been Avoided through Improvements in Cancer Survival? British Medical Journal, 320, 895-898. http://dx.doi.org/10.1136/bmj.320.7239.895

[7] Rossi, S., Cinini, C., Di Pietro, C., Lombardi, C.P., Crucitti, A., Bellantone, R. and Crucitti, F. (1999) Diagnostic Delay in Breast Cancer: Correlation with Disease Stage and Prognosis. Tumori, 76, 559-562.

[8] Rashidi, A. and Rajaram, S.S. (2000) Middle Eastern Asian Islamic Women and Breast SelfExamination: Needs Assessment. Cancer Nursing, 23, 64-70.

http://dx.doi.org/10.1097/00002820-200002000-00010 
[9] Rajaram, S.S. and Rashidi, A. (1999) Asian-Islamic Women and Breast Cancer Screening: A Socio-Cultural Analysis. Women \& Health, 28, 45-58.

http://dx.doi.org/10.1300/J013v28n03_04

[10] Al-Sharbatti, S.S., Shaikh, R.B., Mathew, E. and Al-Biate, M.A.S. (2013) Breast Self-Examination Practice and Breast Cancer Risk Perception among Female University Students in Ajman. Asian Pacific Journal of Cancer Prevention, 14, 4919-4923. http://dx.doi.org/10.7314/APJCP.2013.14.8.4919

[11] Elobaid, Y.E., Aw, T.C., Grivna, M. and Nagelkerke, N. (2014) Breast Cancer Screening Awareness, Knowledge, and Practice among Arab Women in the United Arab Emirates: A Cross-Sectional Survey. PLoS ONE, 9, e105783. http://dx.doi.org/10.1371/journal.pone.0105783

[12] Abduelkarem, A., Saif, F., Saif, S. and Alshoaiby, T. (2015) Evaluation of Breast Cancer Awareness among Female University Students in University of Sharjah, UAE. Advances in Breast Cancer Research, 4, 9-21. http://dx.doi.org/10.4236/abcr.2015.41002

[13] Salat, S.A., Rather, A., Ahmad, S. and Khan, A.B. (2010) Breast Cancer Awareness among Females in a Developing World-A Study from Kashmir. East and Central African Journal of Surgery, 15, 16-21.

[14] Sadler, G.R., Ko, C.M., Cohn, J.A., White, M., Weldon, R. and Wu, P. (2007) Breast Cancer Knowledge, Attitudes, and Screening Behavior among African American Women: The Black Cosmetologists Promoting Health Program. BMC Public Health, 7, 57.

[15] Somdatta, P.P. and Baridalyne, N.N. (2008) Awareness of Breast Cancer in Women of an Urban Resettlement Colony. Indian Journal of Cancer, 45, 149-153. http://dx.doi.org/10.4103/0019-509X.44662

[16] Brunswick, N., Wardle, J. and Jarvis, M.J. (2001) Public Awareness of Warning Signs for Cancer in Britain. Cancer Causes Control, 12, 33-37. http://dx.doi.org/10.1023/A:1008975416756

[17] Wardle, J., Waller, J., Brunswick, N. and Jarvis, M.J. (2001) Awareness of Risk Factors for Cancer among British Adults. Public Health, 115, 173-174. http://dx.doi.org/10.1016/S0033-3506(01)00439-5

[18] Grunfeld, E.A., Ramirez, A.J., Hunter, M.S. and Richards, M.A. (2002) Woman's Knowledge and Beliefs Regarding Breast Cancer. British Journal of Cancer, 86, 1373-1378. http://dx.doi.org/10.1038/sj.bjc.6600260

[19] Waller, J, McCaffery, K. and Wardle, J. (2004) Beliefs about the Risk Factors for Cervical Cancer in a British Population Sample. Preventive Medicine, 38, 745-753. http://dx.doi.org/10.1016/j.ypmed.2004.01.003

[20] Robb, K.A., Miles, A., Campbell, J., Evans, P. and Wardle, J. (2006) Can Cancer Risk Information Raise Awareness without Increasing Anxiety? A Randomized Trial. Preventive Medicine, 43, 187-190. http://dx.doi.org/10.1016/j.ypmed.2006.04.015

[21] Habib, F., Salman, S., Safwat, M. and Shalaby, S. (2010) Awareness and Knowledge of Breast Cancer among University Students in Al Madina Al Munawara Region. Middle East Journal of Cancer, 1, 159-166.

[22] Shin, P.T. (2006) Breast Self Examination: Self-Reported Frequency, Quality and Associated Outcomes. Journal of Cancer Education, 21, 175-181.

[23] Godfrey, K., Agatha, T. and Nankumbi, J. (2015) Breast Cancer Knowledge and Breast Self Examination Practices among Female University Students in Kampala, Uganada: A Descriptive Study. Oman Medical Journal, 31, 129-134. http://dx.doi.org/10.1207/s15430154jce2103_18 
Submit or recommend next manuscript to SCIRP and we will provide best service for you:

Accepting pre-submission inquiries through Email, Facebook, LinkedIn, Twitter, etc. A wide selection of journals (inclusive of 9 subjects, more than 200 journals)

Providing 24-hour high-quality service

User-friendly online submission system

Fair and swift peer-review system

Efficient typesetting and proofreading procedure

Display of the result of downloads and visits, as well as the number of cited articles

Maximum dissemination of your research work

Submit your manuscript at: http://papersubmission.scirp.org/ 